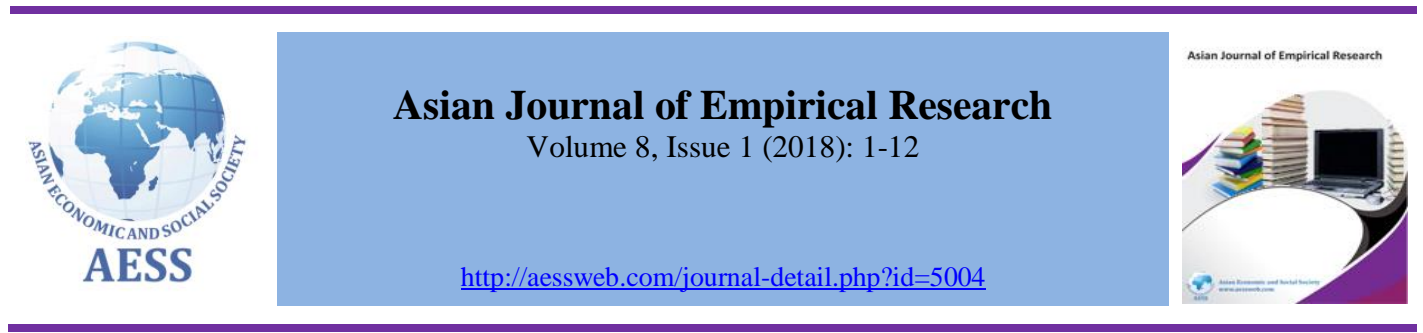

\title{
The effective application of concept mapping in marketing education
}

\section{Chi Hong Leung $\$$, Simone Chung Ling Cheng}

Department of Management and Marketing, The Hong Kong Polytechnic University, Hong Kong, The People's Republic of China.

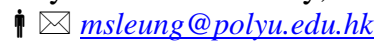

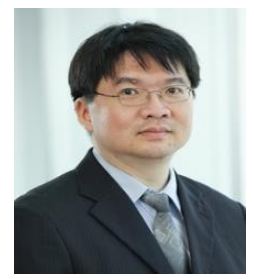

Corresponding author

ARTICLE HISTORY:

Received: $27-$ Oct- 2017

Accepted: 21-Dec-2017

Online available: $05-\mathrm{Jan}-2018$

\section{Keywords:}

Concept map,

Marketing education,

Teaching and learning

activities,

Knowledge representation

\begin{abstract}
A concept map represents knowledge hierarchically. Concept mapping facilitates meaningful learning because it helps to 1) identify understanding, misconceptions, conceptual change, 2) facilitate collaboration and cooperative learning, 3) assess learning of students, and 4) organize and present information. This paper proposes a number of teaching and learning activities with concept mapping. After they were implemented in two marketing classes in a university, both the survey and quiz were used to verify its effectiveness. In the survey, 162 students had positive attitudes to concept mapping with the grand mean of 4.1 in the Likert scale from 1 (strongly disagree) to 5 (strongly agree). The quiz results (with the full mark $=30$ ) also showed that there was academic improvement in two classes with the average scores changing from 17.5 to 24.3 and from 16.5 to 24.5 respectively. These positively proved that concept maps could facilitate teaching and learning activities and improve students' academic performance significantly.
\end{abstract}

\section{Contribution/ Originality}

Various teaching and learning activities with concept maps were used in marketing classes. Positive attitudes to concept mapping found in the survey and academic improvement revealed in quizzes proved that concept maps could enhance teaching and learning in marketing subjects.

DOI: 10.18488/journal.1007/2018.7.1/1007.1.1.12

ISSN (P): 2306-983X, ISSN (E): 2224-4425

CrossMark

How to cite: Chi Hong Leung and Simone Chung Ling Cheng (2018). The effective application of concept mapping in marketing education. Asian Journal of Empirical Research, 8(1), 1-12.

(C) 2018 Asian Economic and Social Society. All rights reserved 


\section{INTRODUCTION}

A concept map allows individuals to convey and describe their understandings of concepts. Concept maps are visual layouts that represent knowledge in a hierarchical structure of concepts and their relationships. A typical concept map illustrates concepts (as nodes on the map) and they are connected by relationship (as lines on the map) to form propositions and semantic networks. An example of a concept map is shown in Figure 1.

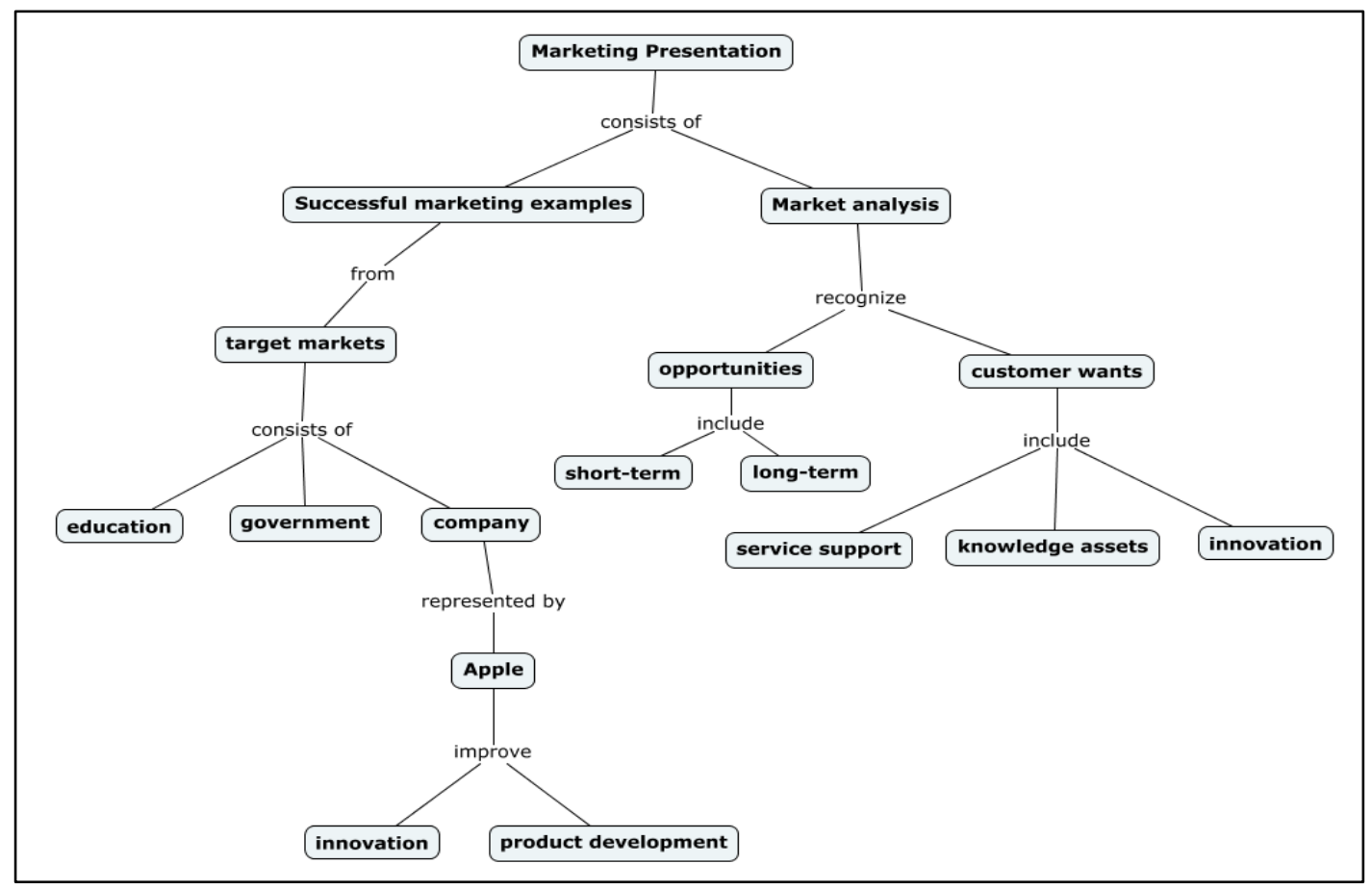

Figure 1: An example of a concept map used for teaching marketing

As a schematic device, a concept map represents a number of concept meanings that are entrenched in a propositional framework in which concepts and ideas are connected (Novak and Gowin, 1984). Concepts designated by labels are perceived regularity in objects or events, or their records (Novak and Cañas, 2006). A particular concept is shown as a circle or box in a concept map and relationships between them are represented by connecting lines. Labels on these lines describe the relationships. Propositions are formed by such concept-link-concept triples that are meaningful representations about objects and events (see Figure 2).

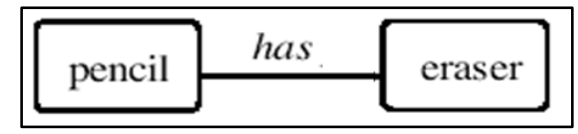

Figure 2: An example of a proposition formed by a concept-link-concept triple

A concept map is usually represented hierarchically with specific concepts at the bottom and generic concepts at the top. Through the arrangement of relevant knowledge a concept map is developed in a specific context to focus on a particular question (Liu et al., 2011; Novak and Gowin, 1984). Hierarchies are branching structures showing categorical relationships between subordinate and superordinate concepts (Lee et al., 2013; McClure et al., 1999). In education the three fundamental usages of a concept map include enhancing learning, supporting critical thinking and deciding prior knowledge. 
Concept maps are developed based on the learning psychology (Ausubel, 1968; Ausubel et al., 1978). The assimilation theory suggests that learning takes place when a learner assimilates fresh concepts and their propositions into the existing conceptual structure. This knowledge structure built by the student is the cognitive structure. Based on the schema theory, knowledge in our minds is in the format of mental constructs of ideas (Armbruster, 1996). The three basic principles of the schema theory state that 1) the memory is organized schematically and semantically, 2) schemas consist of organizations of interconnected concepts, and 3) abstract templates (schema) are subconsciously extracted based on specific experiences. Concept maps are able to foster meaningful learning and the things to be learnt should be conceptually clear and related to prior knowledge of a learner. Thus, as an evaluation tool, a concept map is effective in identification of both valid and invalid concepts held by learners.

The first usage of a concept map is to enhance learning. There are three conditions for meaningful learning (Ausubel, 1968). The first condition is that learning materials should be clear conceptually and presented in a manner related to learners' previous knowledge. The second condition is that learners should have relevant previous knowledge while the third condition is that learners should select to learn meaningfully. A concept map can identify general concepts before instruction in more detailed concepts to meet this condition. Learning tasks can be sequenced through gradually more explicit knowledge embedded in developing concept maps. Students can learn in a more meaningful manner with concept maps. Meaningful learning requires the integration of thoughts and ideas constructively (Niehaus, 1994). When students gradually rebuild their knowledge and form a more complicated structure of interrelated concepts, meaningful learning is engagued (Bala et al., 2016; Quinn et al., 2003). New knowledge is grafted onto an existing structure for meaningful learning and a concept map can assist in mediation of shared cognition (Niehaus, 1994).

The second usage of concept maps is to support critical thinking and encourage various cognitive skills like self-regulation, explanation, inference, interpretation and analysis (Alkhateeb et al., 2016; Vacek, 2009) and these skills challenge learners to think more critically. Concept maps are a kind of metacognitive learning strategy supporting critical thinking that is self-regulatory judgment and a purposeful process.

The third usage of a concept map is to decide prior knowledge. Learners draw concept maps to show their alternative concepts of a subject and teachers can diagnose them (Roberts and Johnson, 2015; Ross and Munby, 1991). A concept map can find and illustrate the alternative concepts used by students to explain the subject matter. Learners may develop their concepts deficiently and incompletely and these lead to misunderstanding. As an educational tool, a concept map can externalize and ascertain what a student already has learnt falsely and the instructor may correct them.

In education concept maps can be used practically as tools for supporting learning, enhancing collaboration among students, assessing learning, presenting information and developing curriculum. To support learning, a concept map is usually used as a study aid and for note taking. Concept mapping is creative because students have to exert effort to clarify meanings, identify essential concepts and their relationships. It enhances reflection on students' understanding and knowledge and it assists teachers in focusing attention on students' learning needs (Novak and Gowin, 1984). Students interact with the subject matter mentally and concept mapping is the key to their academic achievement. Concept mapping can be seriously enhanced when an instructor promotes active enquiry and organization (Cañas et al., 2001). To practise active enquiries, a teacher may ask questions, prompt explanation or encourage students to formulate questions about the subject matter. Learner attitudes and achievement are constructively influenced by the application of concept maps (Horton et al., 1993). In addition, concept maps can motivate learning and find out misconceptions (Mahler et al., 1991).

Moreover, concept maps can be integrated into collaborative learning. A number of students may cooperatively construct a concept map. Collaborative concept mapping can enhance reasoning and debate in the communication among learners (Rafiei and Kardan, 2015; Van Boxtel, et al., 1997, 2000; 
Chinn et al., 2000). A concept map enables learners to think and reason together and enhance meaningful learning because it promotes discussion effectively concerning interrelationships among concepts. Concept maps assist learners in communication with each other and provoke their collaboration and interaction. Concept mapping enhances debate, questioning and discussion (Stoyanova and Kommers, 2002; Wu et al., 2015). To facilitate the modification of a concept map in collaborative learning, there are computer programmes for creating, editing and sharing concept maps conveniently. IHMC Cmap Tools (https://cmap.ihmc.us) is free software for this purpose (see Figure 3 ). Instructors and learners may use this kind of computer tools to draw and edit concept maps for various teaching and learning activities easily.

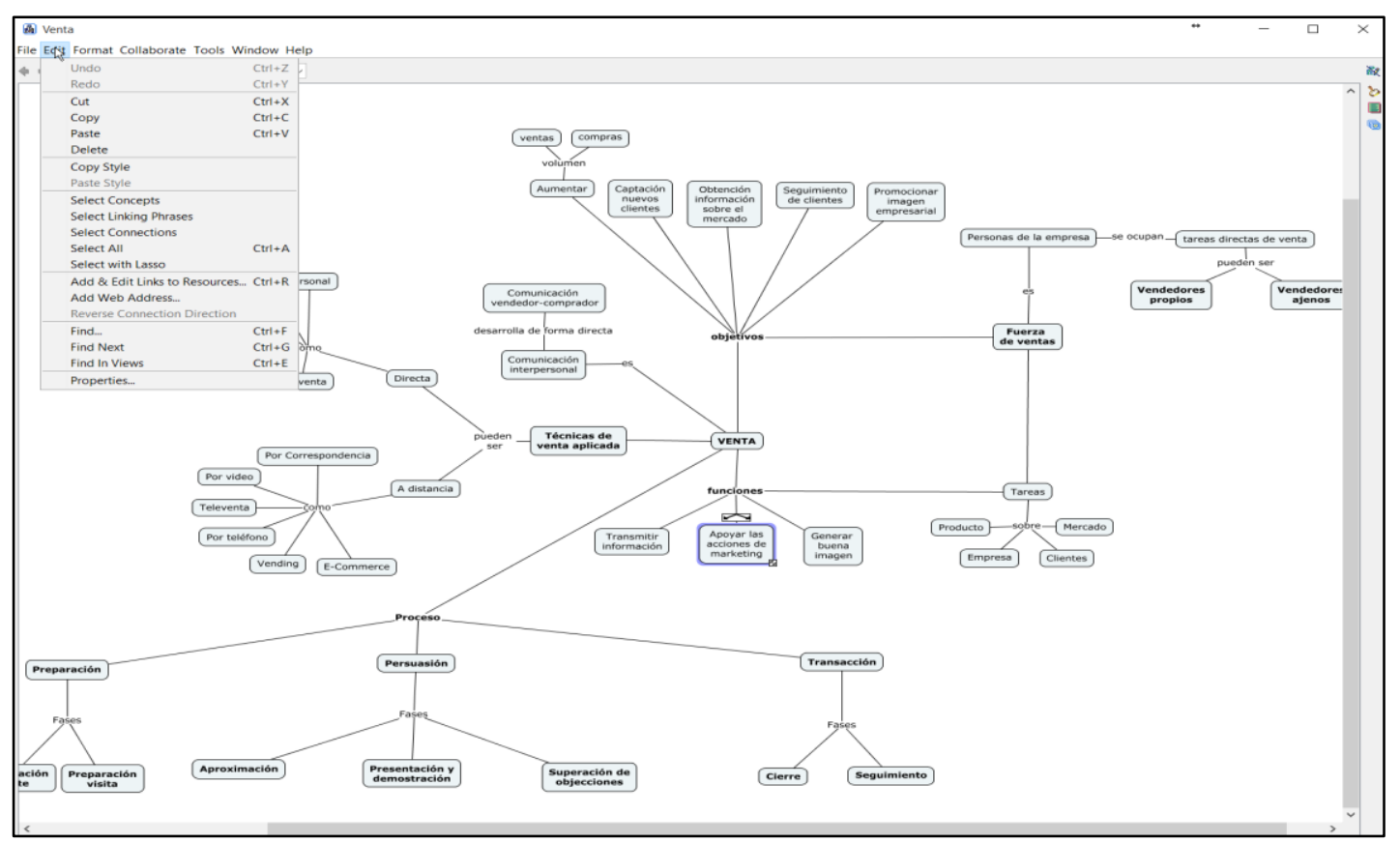

Figure 3: IHMC Cmap tools

Furthermore, concept maps can assess learning. A concept map demonstrates changes of students' knowledge structure when it is used as ongoing evaluation of knowledge. Traditional assessments like essay and multiple choice questions can be reliable and objective but leaners' responses are affected by the context of the items, and they cannot assess knowledge structure of students. A concept map offers a balance and it provides teachers with an objective tool because it is sensitive to learners' knowledge structure and context independent (Trochim, 1989).

Concept maps may also organize and present information. A concept map is most effective because it makes explicit the relationships among concepts known by students and provides a framework into which a new concept can be incorporated. For example, as an advance organizer, a concept map may be displayed at the introduction chapter of textbooks (see Figure 4). A teacher may use it to present an overview of various topics in the subject. An advance organizer addresses issues of learning transfer on a larger scale. The capability of transfer learning largely depends on metacognition constructed through learning strategies assisting learners in reflection on the learning process.

In addition, concept maps can plan a curriculum. Concepts and knowledge central to a subject can be outlined by a concept map and the relationships between generic and specific knowledge can be shown as well. Concept mapping may be used a road map helping learners to select properly what subjects to be taken (Novak and Gowin, 1984) and it may be used at several levels including lectures, case studies, and laboratories. Development of a curriculum involves collaboration between teachers and 
learners. Concept maps allow teachers from different disciplines to attain consensus when they prepare interdisciplinary subjects, and help to create interdisciplinary and integrated subjects. A concept map is used as a communication tool to explain conceptual relationships serving as educational objectives for reconceptualization of their subject matters (Edmondson, 1995; Kaddoura et al., 2016).

The rest of this paper will first discuss the problems encountered by marketing students and how they can be solved by the application of concept maps. The results of the survey reflecting the students' attitudes to concept maps and those of quizzes measuring the change of academic performance caused by the application of concept maps will be shown and discussed. Finally, the insights gained from this empirical research will be presented at the end of the paper.

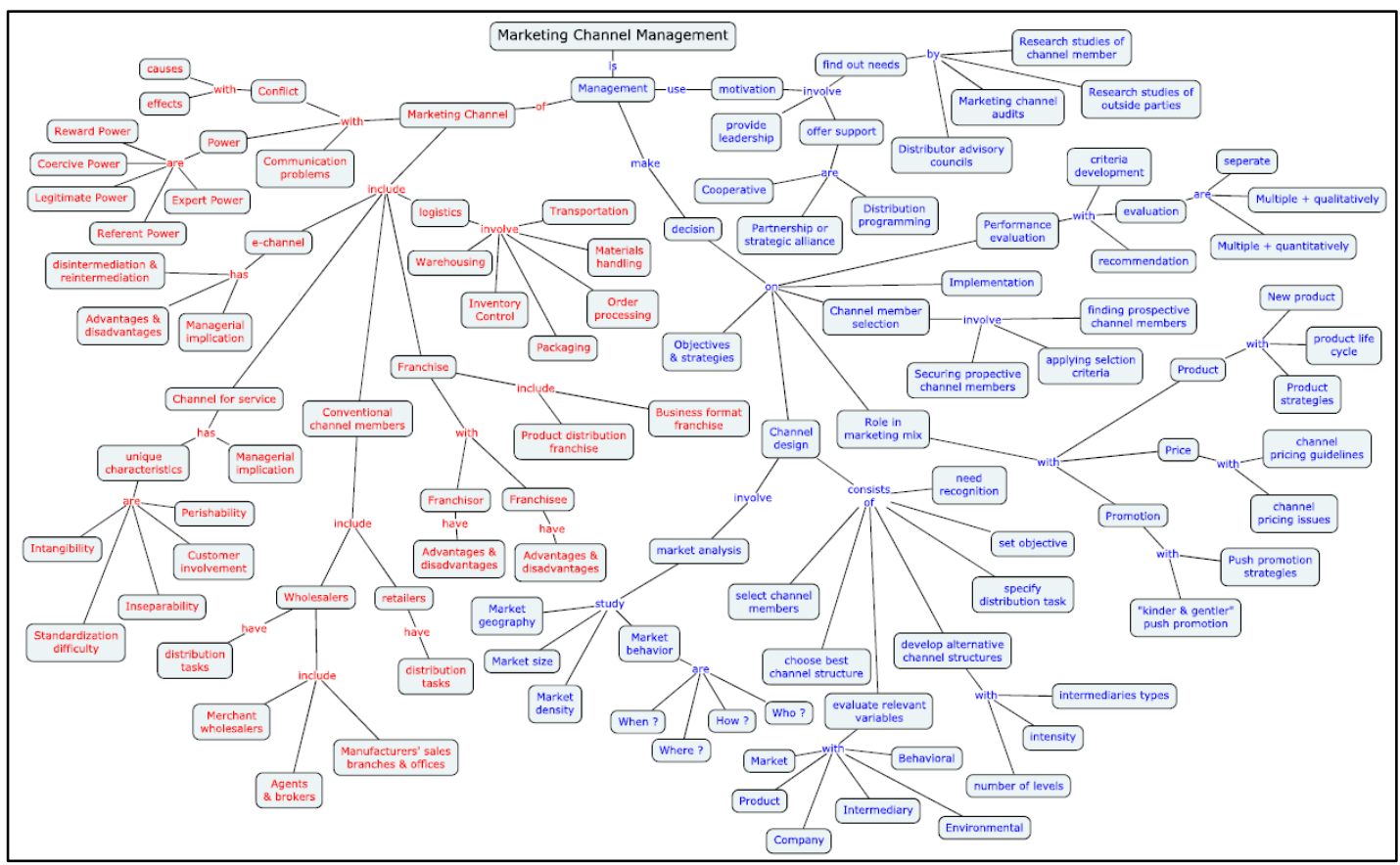

Figure 4: An example of a concept map used as an advance organizer

\section{PROBLEMS IN LEARNING MARKETING}

Students taking marketing subjects usually come across the study problems that can be alleviated by the usage of concept mapping in teaching and learning activities. First, there are a lot of jargons learnt by students in a typical marketing subject. For example, in the subject of Introduction to Marketing, there are, at least, 300 marketing terms learnt by students. Traditional textbooks and lectures usually present these terms straightforwardly and students need an organized way to study and understand these marketing terms. Second, these marketing terms look like plain English but their meanings are very specific in the domain of marketing. For example, when students encounter the marketing terms like "value proposition" and "segmentation base" in an examination question, they may not be aware of their specific meanings. Students need an organized knowledge structure to remind them of the meanings of these terms and their relationships. Third, usually students feel confused with these terms especially when they are learnt in the same lecture or the same chapter of the textbook (e.g. width, length and depth of a product line). Students need an organized knowledge structure to understand the similarities and differences among these terms.

Concept maps can be used to solve these problems particularly and improve students' learning performance. Following are some suggested application of concept maps in marketing subjects. First, at the beginning of a semester, an instructor may prepare a concept map showing the relationships of 
all important topics covered in a subject like the one shown in Figure 4. This not only provides an overview of the syllabus of the subject but also helps students to recognize and learn concept maps. It may be the first time for students to encounter a concept map and the instructor should explain how to read and interpret the meaning conveyed by a concept map.

Second, concept maps may substitute note taking. In each lesson an instructor may distribute worksheets to students. The worksheet shows a concept map illustrating the essential concepts at the top level and students are asked to complete it during the lesson. This learning tool helps students to pay attention to the lecture and learn how to build concept maps before students become familiar with the use of concept maps for academic purposes.

Third, concept mapping may become parts of assessment. For example, students are required to submit a concept map with an essay. The concept map shows the logical flow of a student's thoughts discussed in the essay. This helps students to prepare and review their work in an efficient manner. In group projects, concept maps are able to enhance the communication among group members. For example, each member is responsible for a task in a marketing plan and they may first prepare a concept map at the top level initially and then each member may construct various parts (like each element in marketing 4Ps) of the concept map at the middle and low levels in a cooperative manner. Concept maps can be used for brainstorming and generating information for collaboration. Concept mapping facilitates collaborative learning and students can share their ideas for discussion efficiently.

Scoring of a concept map is based on the structure and components. Marks are given according to valid propositions, hierarchical levels, the number of branching and specific examples (Novak and Gowin, 1984). Progressive differentiation is shown by the number of branching and the extent of subsumption is reflected by the number of hierarchical levels. Although the scoring technique is usually time-consuming, it really provides a lot of data about a student's knowledge concepts.

Other scoring methods were applied following the original scoring system proposed by Novak and Gowin. For instance, the same component may be scored differently with weight (Pearsall et al., 1997). The branching ability of a student reflects the student's breadth of knowledge while the capability of building hierarchies reflects the depth of students' knowledge (Markham et al., 1994). Some suggest that scoring of valid interconnections among concepts only is not supportive because it contradicts with the constructivist theory underling the use of concept maps as learning tools (Kinchin, 2001) and they support a qualitative approach to evaluating concept maps primarily as a function of thoughts created.

Fourth, for revision purpose like the exam preparation, students may be asked to construct concept maps illustrating their answers to past exam questions. An instructor can evaluate their concept maps and find out their conceptual mistakes if any. Usually when answers are presented in the traditional textual format, the instructor may only recognize their mistake superficially. A concept map presented by a student allows the instructor to understand their thoughts and it becomes possible to identify their misconceptions. For example, when a student uses the term "production line" incorrectly, it may be just a spelling mistake of "product line" simply. But on the concept map the student may connect it to other irrelevant concepts and the instructor can recognize such a misconception readily.

\section{METHODOLOGY}

The authors taught two marketing subjects Introduction to Marketing and Marketing Channel Management in the academic year 2016 - 2017. The first subject is usually studied by beginners of marketing and they will come across of a lot of marketing terms in complicated relationships. The second subject is relatively difficult for most marketing students because of the unique characteristics of this subject. Unlike other marketing subjects involving issues related to consumers, this subject covers a lot of issues of human resources management like resolving conflicts among channel members and the details of marketing channels are usually not known by students in the daily life. 
Students are not familiar with these marketing channel issues and get confused with them. The applications of concept mapping mentioned in Section 2 were attempted in order to alleviate their academic problems in these two subjects.

After finishing all the lessons in the seminar, a total of 162 students in two subjects were invited to participate in the survey (see Table 1). The survey was used to collect their attitudes to concept mapping. In addition, there was a mid-term test with 30 multiple choice questions testing the correctness of students' concepts in the subject Introduction to Marketing.

In Appendix A, there are two examples of multiple choice questions to illustrate how they can verify students' marketing concepts. There are several elements in promotion mix including advertising and sales promotion. When answering the example question 1 , some students get confused with the concept of sales promotion that includes showing how to use a product. However, TV commercial is advertising, instead of sales promotion. When a student does not have a clear concept, the answer will be wrong. When answering the example question 2, some students have a misconception that only the concentrated strategy involves one marketing mix. Although the undifferentiated strategy (i.e., mass marketing) does not need to perform segmentation, a particular marketing mix is still required for the marketing plan.

\section{RESULTS OF SURVEY AND QUIZZES}

Table 1 shows the survey questions and average responses in the Likert scale from 1 (strongly disagree) to 5 (strongly agree). This survey result shows that students found concept maps useful in various teaching and learning activities. Concept maps can assist students to understand lecturers and acquire new knowledge. A concept map also helps learners to present knowledge and facilitate collaboration among students themselves. Moreover, a concept map can break through the communication barriers between students and an instructor because the instructor can understand what students think and correct their mistakes.

Table 1: Students' attitudes to concept mapping in teaching and learning activities

\begin{tabular}{lc}
\hline \multicolumn{1}{c}{ Questions } & $\begin{array}{c}\text { Average Score } \\
(\mathbf{n = 1 6 2})\end{array}$ \\
\hline A concept map helps you to enhance meaningful learning. & 4.3 \\
A concept map helps you to understand lectures. & 4.0 \\
A concept map visualizes complicated ideas and makes learning easier. & 3.8 \\
A concept map helps you to think and learn deeply. & 4.2 \\
A concept map facilitates communication among members in your group. & 3.9 \\
A concept map is a useful tool for sharing with others. & 4.4 \\
A concept map enhances your understanding the comments from your & 4.3 \\
instructor. & 4.1 \\
You like to use concept maps in other subjects. & 4.1 \\
\hline
\end{tabular}

In Table 2, the quiz results of two subjects in the current academic year were compared with those of the same subjects in the previous academic year. The results of these two quizzes statistically proved that the application of concept maps is able to improve students' academic performance. Both students and instructors can use concept maps in their teaching and learning activities. A concept map can be used in marketing subjects that involves complicated concepts and their interrelationships. 
Table 2: Results of quizzes

\begin{tabular}{|c|c|c|c|c|c|}
\hline \multicolumn{3}{|c|}{$\begin{array}{l}\text { Average score of Introduction to Marketing } \\
\text { (Full mark =30) }\end{array}$} & \multicolumn{3}{|c|}{$\begin{array}{l}\text { Average score of Marketing Channel } \\
\text { Management (Full mark = 30) }\end{array}$} \\
\hline $\begin{array}{l}\text { Concept map } \\
\text { not applied } \\
(\mathrm{n}=121)\end{array}$ & $\begin{array}{c}\text { Concept map } \\
\text { applied } \\
(\mathrm{n}=109)\end{array}$ & Significance & $\begin{array}{c}\text { Concept map not } \\
\text { applied } \\
(\mathrm{n}=56)\end{array}$ & $\begin{array}{c}\text { Concept map } \\
\text { applied } \\
(\mathrm{n}=53)\end{array}$ & Significance \\
\hline 17.5 & 24.3 & 0.010 & 16.5 & 24.5 & 0.023 \\
\hline
\end{tabular}

\section{CONCLUSION}

Ausubelian educational theory states that teaching students is influenced by their current cognitive structure that is what they already understand. Concept maps are constructed specifically for cognitive structures of students and externalize what they already know (Novak and Gowin, 1984). The internal representation of knowledge is like a network of concepts that are structured and organized (Hiebert and Lefevre, 1986; Hiebert and Carpenter, 1992; Lee et al., 2015; Royer et al. 1993; Pintrich et al., 1993). In addition, the topic can be understood better if there were more connections among a number of facts and ideas (Ci and Choi, 2017; Hiebert and Carpenter, 1992; Hiebert and Lefevre, 1986). Learners can activate information when they perform activities in a knowledge domain and knowledge is structured and interconnected well (Fisher and Lipson, 1985; Royer et al., 1993; Prawat, 1989).

A concept map provides a direct way to analyze the structure and organization of a student's knowledge in a certain domain (Williams, 1998). Concept maps can measures important features of students' declarative knowledge and represent explicitly and develop students' unique experiences (Edmondson, 2000). Knowledge in education is based mostly on a framework of concepts and propositions and the construction of new knowledge occur after meaningful learning (Novak, 2010). Students' cognitive structure shows students' conceptual understanding and obtains insights into the developmental potential for a particular topic (Novak and Cañas, 2006). A concept map is a useful way to evaluate students' knowledge before and after instruction (Edwards and Fraser, 1983). Concept maps constructed by students can be parts of their portfolios to evaluate their performance and understanding in a topic of study (Novak and Cañas, 2006). Concept maps provide learners with the opportunity to consider the interconnectivity of concepts in a specific domain (Chen et al., 2016; Zimmerman et al., 2011).

According to the learning theory, students are motivated to trigger relevant knowledge in a certain domain. Correspondingly, students are stimulated to access relevant knowledge when they are constructing concept maps during the brainstorming state. The combination of information in concept mapping demonstrates the consolidation of information (Micheli, 1998). Students are motivated to apply, clarify and explore the results obtained from the generated concept maps. Concepts are refined and this stimulates learners to enrich and clarify the complication of acquired knowledge (Micheli, 1998).

Instructors require considering the importance of development of a proper learning environment. Before using concept maps in the classroom, the instructor should provide sufficient time for students to learn how to use and practice concept maps. Practically instructors are encouraged to attempt the application of concept maps with various pedagogical methods to see if they can make the teaching and learning activities more meaningful. A brief training in the first lesson of a semester should be provided to students to familiarize with concept maps (Hirashima et al., 2015; Pailai et al., 2017). This requires maximizing the time available for both instructors and learners to become familiar with concept maps. Instructors also use concept maps in curriculum development and assessment practices and assess if this approach enhance learners to study in a more meaningful way. 
Funding: This study received no specific financial support.

Competing Interests: The authors declared that they have no conflict of interests.

Contributors/Acknowledgement: All authors participated equally in designing and estimation of current research.

Views and opinions expressed in this study are the views and opinions of the authors, Asian Journal of Empirical Research shall not be responsible or answerable for any loss, damage or liability etc. caused in relation to/arising out of the use of the content.

\section{References}

Alkhateeb, M., Hayashi, Y., Rajab, T., \& Hirashima, T. (2016). Experimental use of kit-build concept map system to support reading comprehension of EFL in comparing with selective underlining strategy. International Journal of Advanced Computer Science and Applications, 7(4), 80-87. view at Google scholar / view at publisher

Armbruster, B. (1996). Schema Theory and the design of content-area textbooks. Educational Psychologist, 21(4), 253-276. view at Google scholar / view at publisher

Ausubel, D. P. (1968). Educational psychology: a cognitive view. New York: Holt, Rinehart and Winston. view at Google scholar / view at publisher

Ausubel, D. P., Novak, J. D., \& Hanesian, H. (1978). Educational psychology: a cognitive view (2nd ed.). New York: Holt, Rinehart and Winston. view at Google scholar / view at publisher

Bala, S., Dhasmana, D. C., Kalra, J., Kohli, S., \& Sharma, T. (2016). Role of concept map in teaching general awareness and pharmacotherapy of HIV/AIDS among second professional medical students. Indian Journal of Pharmacology, 48(1), S37-S40. view at Google scholar / view at publisher

Cañas, A. J., Ford, K. M., Novak, J. D., Hayes, P., Reichherzer, T., \& Niranjan, S. (2001). Online concept maps: Enhancing collaborative learning by using technology with concept maps. The Science Teacher, 68(4), 49-51. view at Google scholar

Chen, C. H., Chou, Y. Y., \& Huang, C. Y. (2016). An augmented-reality-based concept map to support mobile learning for science. The Asia-Pacific Education Researcher, 25(4), 567-578. view at Google scholar / view at publisher

Chinn, C. A., O'Donnell, A. M., \& Jinks, T. S. (2000). The structure of discourse in collaborative learning. Journal of Experimental Education, 69(1), 77-97. view at Google scholar

Ci, C., \& Choi, S. (2017). How to manage a city's image using the brand concept map and network analysis: A case of Seoul. Quality \& Quantity, 51(6), 2441-2456. view at Google scholar / view at publisher

Edmondson, K. (2000). Assessing Science Understanding through Concept Maps. In J Mintzes, J. Wandersee \& J. Novak (Eds.), Assessing Science Understanding (pp. 19-40). San Diego: Academic Press. view at Google scholar / view at publisher

Edmondson, K. M. (1995). Concept mapping for the development of medical curricula. Journal of Research in Science Teaching, 32(7), 777-793. view at Google scholar / view at publisher

Edwards, J., \& Fraser, K. (1983). Concept maps as reflectors of conceptual understanding. Research in Science Education, 13(1), 19-26. view at Google scholar / view at publisher

Fisher, K. M., \& Lipson, J. I. (1985). Information processing interpretation of errors in college science learning. Instructional Science, 14(1), 49-74. view at Google scholar / view at publisher

Hiebert, J., \& Carpenter, T. P. (1992). Learning and teaching with understanding. In D.A. Grouws (Ed.) Handbook of Research on Mathematics Teaching and Learning (pp. 65-97). New York: Macmillan. view at Google scholar

Hiebert, J., \& Lefevre, P. (1986). Conceptual and procedural knowledge in mathematics: An introductory analysis. In J. Hiebert (Ed.), Conceptual and procedural knowledge: The case of mathematics (pp. 1-27). Hillsdale, NJ: Lawrence Erlbaum Associates. view at Google scholar I view at publisher

Hirashima, T., Yamasaki, K., Fukuda, H., \& Funaoi, H. (2015). Framework of kit-build concept map for automatic diagnosis and its preliminary use. Research and Practice in Technology Enhanced Learning, 1(1), 1-21. view at Google scholar / view at publisher 
Horton, P. B., McConney, A. A., Gallo, M., Woods, A. L., Senn, G. J., \& Hamelin, D. (1993). An investigation of the effectiveness of concept mapping as an instructional tool. Science Education, 77(1), 95-111. view at Google scholar / view at publisher

Kaddoura, M., Van-Dyke, O., \& Yang, Q. (2016). Impact of a concept map teaching approach on nursing students' critical thinking skills. Nursing \& Health Sciences, 18(3), 350-354. view at Google scholar / view at publisher

Kinchin, I. M. (2001). If concept mapping is so helpful to learning biology, why aren't we all doing it? International Journal of Science Education, 23(12), 1257-1269. view at Google scholar / view at publisher

Lee, S., Park, Y., \& Yoon, W. C. (2015). Burst analysis for automatic concept map creation with a single document. Expert Systems with Applications, 42(22), 8817-8829. view at Google scholar I view at publisher

Lee, W., Chiang, C. H., Liao, I. C., Lee, M. L., Chen, S. L., \& Liang, T. (2013). The longitudinal effect of concept map teaching on critical thinking of nursing students. Nurse Education Today, 33(10), 1219-1223. view at Google scholar / view at publisher

Liu, C. C., Chen, H. S. L., Shih, J. L., Huang, G. T., \& Liu, B. J. (2011). An enhanced concept map approach to improving children's storytelling ability. Computers \& Education, 56(3), 873-884. view at Google scholar / view at publisher

Mahler, S., Hoz, R., Fischl, D., Tov-Ly, E., \& Lernau, O. (1991). Didactic use of concept mapping in higher education: Application in medical education. Instructional Science, 20(1), 25-47. view at Google scholar / view at publisher

Markham, K. \& Mintzes, J., \& Jones, M.G. (1994). The concept map as a research and evaluation tool: FUliher evidence of validity. Journal of Research in Science Teaching, 31(1), 91- 101. view at Google scholar / view at publisher

McClure, J., Sonak, B., \& Suen, H. (1999). Concept map assessment of classroom learning: reliability, validity and logistical practicality. Journal of Research in Science Teaching, 36(4),475-492. view at Google scholar / view at publisher

Micheli, L. (1998). Concept mapping in evaluation practice and theory: a synthesis of current empirical research. Unpublished Master Thesis, University of Ottawa, Canada. view at Google scholar

Niehaus, J. (1994). Learning by frame working: Increasing understanding by showing students what they already know. Journal of College Science Teaching, 24(2), 22-25. view at Google scholar

Novak, J. D. (2010). Learning, creating, and using knowledge: concept maps as facilitative tools in schools and corporations. Journal of e-Learning and Knowledge Society, 6(3), 21-30. view at Google scholar / view at publisher

Novak, J. D., \& Cañas, A. J. (2006). The origins of the concept mapping tool and the continuing evolution of the tool. Information Visualization, 5(3), 175-184. view at Google scholar / view at publisher

Novak, J. D., \& Gowin, D. B. (1984). Learning How to Learn. New York and Cambridge, UK: Cambridge University Press. view at Google scholar / view at publisher

Pailai, J., Wunnasri, W., Yoshida, K., Hayashi, Y., \& Hirashima, T. (2017). The practical use of KitBuild concept map on formative assessment. Research and Practice in Technology Enhanced Learning, 12(1), 1-23. view at Google scholar / view at publisher

Pearsall, N. R., Skipper, J., \& Mintzes, J. (1997). Knowledge restructuring in the life sciences: A longitudinal study of conceptual change in biology. Science Education, 81(2), 193-215. view at Google scholar / view at publisher

Pintrich, P. R., Marx, R. W., \& Boyle, R. B. (1993). Beyond cold conceptual change: the role of motivational beliefs and classroom contextual factors in the process of conceptual change. Review of Educational Research, 63(2), 167-199. view at Google scholar / view at publisher

Prawat, R. S. (1989). Promoting access to knowledge, strategy, and disposition in students: A research synthesis. Review of Educational Research, 59(1), 1-41. view at Google scholar / view at publisher

Quinn, H. J., Mintzes, J. J., \& Laws, R. A. (2003). Successive concept mapping. Journal of College Science Teaching, 33(3), 12-16. view at Google scholar 
Rafiei, M., \& Kardan, A. (2015). A novel method for expert finding in online communities based on concept map and PageRank. Human-centric Computing and Information Sciences, 5(1), 1-18. view at Google scholar / view at publisher

Roberts, R., \& Johnson, P. (2015). Understanding the quality of data: a concept map for the thinking behind the doing. Scientific Practice Curriculum Journal, 26(3), 345-369. view at Google scholar / view at publisher

Ross, B., \& Munby, H. (1991). Concept mapping and misconceptions: a study of high school students' understanding of acids and bases. International Journal of Science Education Studies in Mathematics, 13(1), 11-24. view at Google scholar / view at publisher

Royer, J. M., Cisero, C. A., \& Carlo, M. S. (1993). Techniques and procedures for assessing cognitive skills. Review of Educational Research, 63(2), 201-243. view at Google scholar / view at publisher

Stoyanova, N., \& Kommers, P. (2002). Concept mapping as a medium of shared cognition in computer-supported collaborative problem solving. Journal of Interactive Learning Research, 13(1-2), 111-133. view at Google scholar

Trochim, W. M. (1989). An introduction to concept mapping for planning and evaluation. Evaluation and Program Planning, 12(1), 1-16. view at Google scholar / view at publisher

Vacek, J. E. (2009). Using a conceptual approach with concept mapping to promote critical thinking. Journal of Nursing Education, 48(1), 45-48. view at Google scholar / view at publisher

Van Boxtel, C., Van Der Linden, J., \& Kanselaar, G. (1997). Collaborative construction of conceptual understanding: Interaction processes and learning outcomes emerging from a concept mapping and a poster task. Journal of Interactive Learning Research, 8(3-4), 341-361. view at Google scholar

Van Boxtel, C., Van Der Linden, J., \& Kanselaar, G. (2000). Collaborative learning tasks and the elaboration of conceptual knowledge. Learning and Instruction, 10(4), 311-330. view at Google scholar

Williams, C. G. (1998). Using concept maps to assess conceptual knowledge of function. Journal for Research in Mathematics Education, 29(4), 414-421. view at Google scholar / view at publisher

Wu, S. Y., Chen, S. Y., \& Hou, H. T. (2015). Exploring the interactive patterns of concept map-based online discussion: A sequential analysis of users' operations, cognitive processing, and knowledge construction. Interactive Learning Environments, 24(8), 1-17. view at Google scholar / view at publisher

Zimmerman, R., Maker, C. J., Gomez-Arizaga, M. P., \& Pease, R. (2011). The use of concept maps in facilitating problem solving in earth science. Gifted Education International, 27(3), 274-287. view at Google scholar / view at publisher 


\section{Appendix}

Appendix A - Examples of two questions testing the correctness of students' concepts

Example question 1 is/are typical example(s) of sales promotion.

(i) A TV commercial showing how to use a new mobile phone

(ii) A demonstrator showing how to cook a kind of food in a supermarket

(iii) Cash rebate offered by an electronic appliance store
A) (ii) only
B) (iii) only
C) (i) and (ii)
D) (ii) and (iii)
E) (i) and (iii)

Example question 2

A marketer applies one marketing mix in the marketing plan because he uses the strategy of segmentation.
(i) undifferentiated
(ii) differentiated
(iii) concentrated
A) (ii) only
B) (iii) only
C) (i) and (ii)
D) (ii) and (iii)
E) (i) and (iii) 